\title{
¿Qué es el neodesarrollismo? Una visión crítica. Argentina y Brasil
}

\section{What is neo-developmentism? A critical view. Argentina and Brazil}

Claudio Katz*

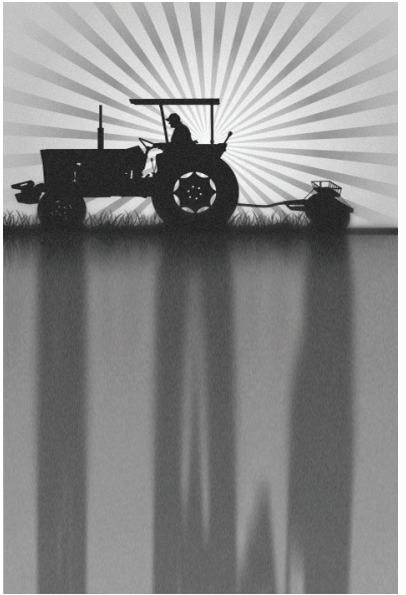

Resumen: El ensayo neodesarrollista de Argentina ha quedado afectado por la renuncia a una mayor apropiación estatal de la renta y por los subsidios improductivos a los capitalistas. Se reforzaron los perfiles extractivos y los desequilibrios industriales. Brasil no afrontó crisis y rebeliones de la misma envergadura y su política económica ha sido más conservadora. El neodesarrollismo es un programa de economías medianas afectadas por agroexportaciones, que disuaden la inversión fabril. Se intenta reorientar ese excedente pero se retrocede frente a los conflictos que suscita.

Palabras claves: Modelos económicos. Crisis. Capitalismo. América Latina

\begin{abstract}
Argentina's neo-developmental trial was affected by the renunciation of a larger state appropriation of the income and by the unproductive subsidies to capitalists. Both the extractive profiles and the industrial imbalances were reinforced. Brazil did not face crises and rebellions on the same scale, and its economic policy has been more conservative. Neo-developmentism is a program of medium economies affected by agro-exports that deter the industrial investment. It aims at reorienting that surplus, but it moves backwards when it is faced with the conflicts raised.
\end{abstract}

Keywords: Economic models. Crisis. Capitalism. Latin America.

* Licenciado en Economía, Universidad de Buenos Aires, Argentina. Doctor de la Universidad de Buenos Aires. Facultad de Filosofía y Letras, área Geografia,e-mail: <claudiokatz1@gmail.com>. 


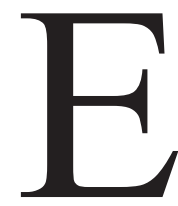

n Argentina se implementó el principal ensayo del neodesarrollista de la última década. El país volvió a encabezar los virajes económicos de la región, como ya ocurrió en los años 50-60 con la sustitución de importaciones y en los 90 con el neoliberalismo extremo. Reafirmó su papel de experimentador de mutaciones significativas en América Latina. Este rol de adelantado es reivindicado por los autores que ponderan el modelo, en comparación a los esquemas ortodoxos de otras economías. ${ }^{1}$

\section{Un corto ensayo}

El esquema intentado en Argentina logró cierta efectividad en la fase inicial del gobierno kirchnerista. Durante ese período (2003-2007) se reunieron las condiciones para lograr alto crecimiento, con baja inflación y recuperación del empleo.

Las políticas neodesarrollistas aportaron un tercer ingrediente a los fundamentos objetivos de este ciclo. El primer determinante fue la depreciación de los salarios y la consiguiente recomposición de la rentabilidad que legó el derrumbe del 2001. El segundo motor de la expansión fue la valorización internacional de las agroexportaciones.

Las iniciativas neodesarrollistas introdujeron cambios en la administración del estado y un nuevo arbitraje entre los grupos dominantes. Pero este curso mantuvo muchos vasos comunicantes con el esquema precedente. Subordinó la meta de reindustrializar a la continuidad de exportaciones primarizadas y apuntaló a los sectores empresarios más internacionalizados.

El modelo limitó inicialmente la valorización financiera y adaptó el rumbo de la economía a la nueva relación social de fuerzas impuesta por la rebelión del 2001. Hubo contemporización con las demandas populares y se recurrió a una mayor escala de asistencialismo.

1. Bresser Pereira, Luiz Carlos. Globalización y competencia. Buenos Aires: Siglo XXI, 2010. p. 129, 141-142. 
Durante cuatro años se pudo gestionar la economía con los parámetros del modelo Bresser-Ferrer. Hubo superávit fiscal primario, alto tipo de cambio, bajas tasas de interés y expansión del consumo. Pero la acelerada disipación de esta coyuntura anticipó el escaso margen existente para mantener ese curso.

En el 2007-2010 comenzó la inflación y se frenó el crecimiento. El modelo persistió con los nuevos impulsos aportados por la introducción de un ingreso universal asistencial y la estatización de los fondos de pensión. Con esas medidas se intentó sostener un esquema ya amenazado por el deterioro de sus principales variables.

Esos desequilibrios emergieron con fuerza a partir del 2011. La inflación se intensificó, la producción se estancó, el déficit fiscal reapareció y fallaron todas las iniciativas implementadas para revertir el declive. El control de cambios, la pesificación y la expansión de la emisión no atenuaron el resquebrajamiento del modelo.

A comienzo del 2014 resurgieron finalmente las tensiones clásicas de la economía argentina que condujeron a las repetidas debacles del pasado. La reiteración de esos colapsos se encuentra actualmente contrarrestada por el limitado nivel de endeudamiento público y privado, la solvencia de los bancos y la continuada valorización de las exportaciones. Por esta razón el PBI se contrae, pero con apuestas a un rebote ulterior. Numerosos capitales internacionales ya preparan su arribo para adquirir empresas. ${ }^{2}$

Sin embargo, la continuidad del proceso neodesarrollista ha quedado severamente afectada por el debilitamiento político-electoral del kirchnerismo. Es muy probable que en los próximos años, Argentina atraviese un giro político semejante al observado al final de los grandes ciclos de las últimas décadas. Ya ocurrió a mitad de los 70, durante los 80 y en el 2001-03. En los tres casos el peronismo registró una convulsión mayúscula y pudo reconstituirse, pero sin recuperar la fidelidad popular que rodeó a su gestación. Ha sobrevivido más que otras fuerzas semejantes de América Latina transitando por una amplia

2. Nuestra visión general en: Katz, Claudio. La economía desde la izquierda I. coyuntura y ciclo, II. Modelo y propuestas. Argenpress, 29 nov. 2013. Disponible en: <http://www.argenpress.info/2013/11/la-economia-desde-la-izquierda-i.html>. 
gama de variantes, que incluyeron el nacionalismo inicial, la radicalidad popular, el giro represivo y el neoliberalismo.

A diferencia de sus antecesores, el kirchnerismo encabezó una administración con fisonomía centro-izquierdista y retórica progresista. Restauró el sistema político, otorgó importantes concesiones democráticas y sociales e improvisó un proyecto diferenciado del peronismo tradicional. Pero no logró generar una identidad política sustituta. ${ }^{3}$

Este período concluye con un giro conservador de adaptación a las demandas del establishment. Este viraje incluye una gran devaluación y achatamientos de los salarios. A la luz de los enormes desequilibrios acumulados durante los últimos años es muy dudosa la persistencia del curso económico actual.

\section{Múltiples desajustes}

La elevada tasa de inflación es la principal manifestación de las tensiones generadas por el modelo. Ese incremento de los precios supera en los últimos seis años la media global o latinoamericana y se ha estabilizado en torno al $25-30 \%$ anual. No decae en las coyunturas recesivas y su porcentaje real fue desconocido durante largo tiempo por la manipulación oficial de las estadísticas. La gestión cotidiana de la economía quedó afectada por esta distorsión de un indicador clave.

El incremento de los precios obedeció inicialmente al reducido nivel de inversión frente a una demanda recompuesta. Ese cuello de botella se reforzó posteriormente por el manejo concentrado de numerosos sectores. La remarcación permitió mantener el nivel general de las ganancias una vez disipada la capacidad ociosa. ${ }^{4}$

3. Nuestro enfoque en: Katz, Claudio. Nuevo escenario, nuevas posibilidades. La Página de Claudio Katz. Textos de Ciencias Sociales, 22 mayo 2014. Disponible en: $<$ http://katz.lahaine.org/?p=230>.

4. Schorr, Martín; Manzanelli, Pablo. Inflación oligopólica. Disponible en: <www.pagina12.com.ar $>$, 24-3. Inflación Página12, Suplementos Cash, 10 mar. 2013. Disponible en: <http://www.pagina12.com.ar/ diario/suplementos/cash/17-6669-2013-03-10.html>. 
Algunos economistas cuestionan este diagnóstico de "inflación por oligopolio", estimando que la carestía deriva de una "puja distributiva" entre empresarios y trabajadores. Argumentan que en otros países la misma concentración de los negocios no se traduce en inflación. ${ }^{5}$

Pero tampoco la disputa social por el ingreso genera allí el mismo incremento de los precios. En esos países los mismos desequilibrios desembocan en otro tipo de tensiones, puesto que el recurso inflacionario no está incorporado al manejo corriente de la actividad. Por simple experiencia, los capitalistas argentinos apelan más a la remarcación que sus pares de otros países. Es una conducta muy asociada con la elevada expatriación de capitales y el manejo de inversiones dolarizadas.

Los rebrotes inflacionarios obedecen, además, a la preeminencia de una estructura exportadora de alimentos que encarece todos los costos agrarios, al compás de la valorización internacional de esos productos. Finalmente, en los últimos años la inflación se intensificó por la decisión oficial de sostener el consumo a través de una intensa emisión. Este ritmo de creación de moneda quedó divorciado del respaldo en divisas y de los montos requeridos para la producción. Por esta razón se acentuó la depreciación del peso.

El déficit fiscal constituye el segundo punto crítico del modelo. Ya se aproxima al 3\% del PBI y afecta duramente a las provincias, que destinan la mitad de sus presupuestos al pago de salarios. Ante la ausencia de financiación el gobierno promueve recortes a los subsidios del transporte y la energía para calmar las presiones del establishment.

El tercer campo de turbulencia ha sido la caldera cambiaria que estalló a fin del 2013. El gobierno implementó la devaluación que pretendía evitar. Intentó contener la estampida cambiaria vendiendo reservas, pero terminó generando una hemorragia que redujo peligrosamente el respaldo de los pesos en circulación.

También se introdujeron formas de control cambiario que los neoliberales cuestionaron a viva voz, culpando al intervencionismo estatal por la "inestabi-

5. Crespo, Eduardo; Fiorito, Alejandro. Es la puja distributiva". Disponible en: <www.pagina12.com. ar>, 17/03. "Es la puja... Página12, suplementos Cash, 17 mar. 2013. Disponible en: <http://www.pagina12. com.ar/diario/suplementos/cash/17-6669-2013-03-10.html>. 
lidad de los mercados". ${ }^{6}$ Pero esa injerencia fue muy acotada y sólo buscó detener las presiones devaluatorias. Como Argentina no fabrica los dólares que utiliza para solventar sus compras externas, necesita algún tipo de regulación estatal cuando las divisas comienzan a escasear.

El gobierno intentó contrapesar el "mercado libre" que manejan los bancos y los exportadores. No violó ninguna ley de la naturaleza, ni tampoco los principios de una economía sana. El control de cambios fue introducido en forma tardía y se manejó con total arbitrariedad. En lugar de penalizar a los especuladores, los funcionarios toleraron la apropiación bancaria de los menguantes dólares.

Después de transitar por todos los rumbos posibles, el gobierno se embarcó en un ajuste que cuestiona todos los principios neodesarrollistas. Elevó drásticamente las tasas de interés y forzó un encarecimiento del crédito que asfixia el consumo. De un estancamiento en la creación de puestos de trabajo se pasó a una coyuntura de menor empleo, en un marco de alta informalidad laboral. Este contexto se ubica muy lejos de la depresión del 2001, pero el modelo se ha quedado sin combustible.

Lo más traumático son las medidas de restricción salarial que convierten a los ingresos populares en la variable de ajuste. La inflación licúa los salarios, las jubilaciones y los programas de gasto social. El gobierno oculta las cifras de pobreza e indigencia para no transparentar que su promedio actual se asemeja a los decenios anteriores. Nadie puede exhibir como un logro de la "década ganada", que la pobreza afecte hoy al trabajador y no al desocupado, o que el asistencialismo evite las situaciones de extrema hambruna.

Argentina ha vivido muchas veces estas coyunturas críticas. Pero las condiciones actuales difieren significativamente en el plano político y económico de los antecedentes traumáticos legados por el "rodrigazo" (1975), la hiperinflación (1989) o el colapso general (2001). La tensión actual no tiene

6. Esta postura difunden economistas ortodoxos como: Melconian, Carlos. Faltan dólares, sobran pesos... Y seguiremos así. La Nación, Economía, 04 ago. 2013. Disponible en: http://www.lanacion.com.ar/1607100-faltan-dolares-sobran-pesos-y-seguiremos-asi>. Ferreres, Orlando (2013). "Cómo salir del camino de la decadencia”. La Nación, Opinión, 05 jul. 2013. Disponible en: <http://www.lanacion.com.ar/1598171-como-salir-del-camino-de-la-decadencia>. 
el alcance del pasado, pero ilustra la impotencia de la receta neodesarrollista para evitar los temblores que atormentan a la economía.

\section{Crisis global y demanda}

Los problemas del esquema ensayado en Argentina son reconocidos por sus propios promotores. Suelen atribuir esas fallas al impacto de la crisis global que irrumpió en el 2008. Afirman que el modelo permitió contrarrestar las consecuencias más dramáticas de esa convulsión, pero sin neutralizar todos sus efectos. Establecen comparaciones con Europa y remarcan las virtudes del crecimiento nacional frente al resto de Sudamérica. ${ }^{7}$

Pero la crisis mundial afecta en forma muy diferente a cada región o país. Basta comparar la prosperidad de China con el derrumbe de Grecia para notar esas disparidades. El contraste que se establece entre Argentina y Europa del Sur olvida que la primera economía soportó en el 2001, el vendaval que actualmente sacude al Viejo Continente. Los ciclos de prosperidad y depresión global no están sincronizados.

Ciertamente el divorcio del mercado financiero internacional y la prioridad asignada al consumo, diferencian al modelo argentino de la apertura neoliberal, imperante en otros países de Sudamérica. Pero el impacto de la crisis mundial ha sido limitado y semejante en ambos casos, dada la afluencia común de divisas que generó la apreciación de las exportaciones. Los precios récord de la soja y los ingresos aportados por la agroexportación durante la última década, superaron en cinco veces el promedio de los 90 y en diez veces la media de los 80 .

Los principales desequilibrios del experimento neodesarrollista radican en el propio modelo. Ese esquema supuso que bastaba con alentar la demanda para incentivar el despegue de un círculo virtuoso de inversión y crecimiento. Inspirados en la heterodoxia keynesiana, sus promotores imaginaron que el simple aliento al consumo impulsaría a toda la economía hacia un sendero de

7. Feletti, Roberto. La crisis global y el futuro de la región. La Nación, Economía, 10 jun. 2013. Disponible en: <http://www.lanacion.com.ar/1596613-la-crisis-global-y-el-futuro-de-la-region>. 
crecimiento auto sostenido. Pero lo que funcionó en el 2003-2007 perdió consistencia en el 2008-2010 y se tornó inviable desde el 2011.

Bajo el capitalismo los empresarios no sólo se interesan por el comportamiento de las ventas. Priorizan las ganancias y evalúan los costos. El empuje del consumo es reactivador en ciertas coyunturas, pero obstruye la rentabilidad en otras circunstancias.

Los heterodoxos suelen cometer una ingenuidad simétrica al ideario neoclásico, al imaginar grandes expansiones de la oferta productiva por el mero repunte de la demanda. Esperan una reacción inviablemente positiva de los empresarios frente a esa mejora, olvidando la gravitación de otras variables como el riesgo o el beneficio. Su idealización del capitalismo les impide percibir las contradicciones de este sistema.

Con esas ilusiones apostaron una y otra vez a la autocorrección del modelo, mediante sencillos empujes de la demanda que terminaron generando impulsos inflacionarios, solventados con elevado gasto público y alta emisión. Lo que funcionó durante la salida de la convertibilidad por la existencia de importantes recursos ociosos, perdió viabilidad en la coyuntura posterior.

Esas políticas permitieron incluso ciertos resultados de corto plazo frente a la recesión del 2009. Aprovecharon la subsistencia de un gran colchón de fondos públicos para reanimar la economía. Pero ese excedente se disipó posteriormente. Cuando en el 2013-2014 desapareció el margen para posponer ajustes, el gobierno recurrió a las políticas ortodoxas de contracción de la demanda, que el neodesarrollismo suele objetar enfáticamente.

\section{La renta convalidada}

El ensayo neodesarrollista ha fallado por la incapacidad del gobierno para incrementar la apropiación estatal de la renta de la soja. Esta medida es una condición insoslayable para estabilizar un modelo de expansión productiva y mejoras sociales. El kirchnerismo pretendió aumentar la captación pública de ese excedente subiendo los impuestos a las exportaciones de la soja (retenciones). Pero fue derrotado en la confrontación del 2008 con el agronegocio y desde ese momento abandonó todo intento de retomar la iniciativa en este campo. 
Ese desenlace marcó un punto de inflexión. No le impidió al gobierno preservar (y recrear) su hegemonía política, pero le quitó al estado los recursos necesarios para la reindustrialización. Persistió cierto crecimiento, pero con los motores del desarrollo totalmente apagados.

Argentina es una economía agroexportadora asentada en la extraordinaria fertilidad de la tierra. Ese ventajoso acervo de recursos naturales constituye una maldición bajo el capitalismo, puesto que establece un alto piso de renta comparativa para cualquier otra inversión. Ninguna actividad ofrece un nivel de rendimiento semejante al agro. Esta asimetría históricamente determinó la preeminencia inicial de la ganadería y los cereales y su reemplazo actual por la soja.

La industria no pudo competir durante la centuria pasada con el latifundio terrateniente y no logra rivalizar en la actualidad con los Pools de Siembra. Un sector primario que ofrecía escasas ofertas de trabajo a los chacareros, ya no crea empleo en la era de la siembra directa. La aglomeración en villas miserias que generaba el éxodo rural del interior ha devenido en informalidad laboral masiva, a partir del deterioro de la industria.

Los distintos proyectos de industrialización que se implementaron desde la segunda mitad del siglo XX apuntaron a contrarrestar esta tendencia a la primarización estructural. Pero todos afrontaron el mismo límite que impone la elevada renta agroexportadora al estrecho beneficio fabril. Como la fertilidad natural de la tierra asegura costos muy inferiores al promedio mundial, la vieja tentación de privilegiar el agro (o a su extensión agroindustrial) invariablemente se renueva.

Esa primacía agroexportadora reapareció con fuerza en las últimas décadas de modernización de la producción agrícola (modificaciones genéticas, agroquímicos, maquinaria de última generación) y aumento de la demanda internacional (por especulación financiera, compras de China-India y agrocombustibles).

Este escenario volvió a disuadir el tibio intento oficial de sostener la actividad fabril, más allá de alguna sustitución de importaciones. Los capitalistas de la soja mantuvieron su renta y el estado se quedó sin los ingresos necesarios para desenvolver un modelo productivo. En estas condiciones el gobierno 
archivó su proyecto y se resignó a gestionar el status quo de una economía sin dinamismo industrial.

Algunos autores extraen otro balance del conflicto con los agrosojeros. Estiman que ese choque derivó en una radicalización progresista del oficialismo e incentivó medidas favorables al modelo neodesarrollista (como la estatización de los fondos de pensión y la asignación universal). ${ }^{8}$

Pero esta caracterización invierte lo ocurrido y no explica los desequilibrios que finalmente empujaron al kirchnerismo al ajuste. Ignora que al renunciar a un manejo mayor de la renta el gobierno perdió el rumbo y se diluyó su proyecto.

Existió otra posibilidad para retomar el control de la renta durante la crisis cambiaria de principios del 2014 que requería especial voluntad política. El gobierno podía intentar en ese momento la nacionalización del comercio exterior, para obligar a los exportadores y financistas a liquidar los dólares acaparados. Pero optó por el libreto convencional.

El control estatal sobre las divisas es imprescindible para superar el status de Argentina como agroexportador de productos básicos. Únicamente el monopolio estatal del comercio exterior asegura la comercialización centralizada de los enormes recursos que tiene el país. Otras instituciones que ya existieron en el pasado - como el IAPI (Instituto Argentino de Promoción del Intercambio) - podrían complementar esta labor, negociando los precios y financiando la siembra o la cosecha. Esas entidades permitirían desvincular los precios locales de las cotizaciones internacionales y contribuirían a contrarrestar la inflación generada por la exportación de alimentos.

El ensayo neodesarrollista socavó su propio despunte al renunciar al único instrumento eficaz para cortar la especulación cambiaria y la facturación fraudulenta de las exportaciones. Eludió comenzar la desprivatización de un ingreso que pertenece a todo el país y que permitiría remodelar la producción

8. Varesi, Gastón. Argentina 2002-2011: neo-desarrollismo y radicalización progresista. Realidad Económica, n. 264, nov.-dic. 2011. Disponible en: <http://pt.scribd.com/doc/99054275/Varesi-Gaston-2011Argentina-2002-2011-Neo-desarrollismo-y-radicalizacion-progresista-en-Realidad-Economica-n$-264 \#$ scribd $>$. 
agropecuaria, frenar la expansión de la frontera sojera, recuperar la ganadería y recrear la vitalidad de los cereales y los cultivos regionales.

\section{Burguesía e inoperancia}

El neodesarrollismo apostó por enésima vez al comportamiento productivo de la burguesía, olvidando los reflejos que ha perfeccionado este sector para fugar capitales, remarcar precios y desinvertir. Las expectativas que todos los gobiernos depositaron en esa franja siempre concluyeron en estruendosas decepciones.

Esa conducta de los capitalistas argentinos obedece a numerosas razones. Ha influido la formación histórica de un sector muy dependiente de la financiación estatal, tradicionalmente débil frente a la oligarquía y muy temeroso de la clase obrera. También incide la frustrada experiencia con la sustitución de importaciones y la pérdida de posiciones frente a Brasil.

Muchos autores suelen constatar periódicamente estos fenómenos, sin extraer ninguna conclusión. A los sumo sugieren que el estado debe ampliar su presencia económica para sustituir esa deserción. Pero ese reforzamiento también generaría tensiones y no podría atravesar ciertos límites, puesto que un modelo de "capitalismo estatal sin capitalistas" carecería de sentido. ${ }^{9}$

La frustración actual es proporcional a las expectativas depositadas en la burguesía local. El kirchnerismo ponderó a ese sector y lo benefició con cuantiosos recursos del estado esperando mayores inversiones. Pero esos subsidios volvieron a engrosar el patrimonio de los amigos del poder, sin ningún rédito productivo para el conjunto de la economía. Cada vez que ese uso parasitario salió a la superficie, el gobierno reemplazó a un favorecido por otro. Todos los grupos privilegiados aumentaron su riqueza a costa del erario público y protegieron su dinero en el exterior.

9. Un reciente ejemplo de estos problemas en: Zaiat, Alfredo. Mariachi, burguesía y el estado. Página12, Economía, 17 nov. 2013. Disponible en: <http://www.pagina12.com.ar/diario/economia/2-233771- 2013-1117.html>. 
La burguesía local participó en los negocios más rentables que le ofreció el kirchnerismo y se retiró cuando debía aportar capital propio. En lugar de "enterrar capital" en inversiones de largo plazo ha preferido embarcarse en operaciones de alta rentabilidad inmediata. Con esa conducta participó en las privatizaciones en los 90 y ahora observa con atención el posible regreso de los fondos de inversión para la reestructuración de las empresas.

El neodesarrollismo no sólo falló por su expectativa en los capitalistas. La última década estuvo signada también por una impotencia mayúscula en el terreno cambiario, impositivo y financiero.

Con el manejo de dólar se experimentaron todas las alternativas de introducción y eliminación de controles. En lugar de forjar un sistema protección de las divisas para las actividades prioritarias, se terminó armando un barroco dispositivo de medidas inútiles.

En el plano impositivo quedó nuevamente congelada la reforma progresiva discutida en incontables oportunidades. Las propuestas para gravar la renta financiera, el juego y las actividades minero-extractivas han sido tan numerosas, como los proyectos para reintroducir los aportes patronales en la previsión social. Se habló hasta el cansancio de estos temas sin ningún correlato en definiciones prácticas.

El colmo de las contradicciones oficiales ha sido la orgullosa política de cancelar deuda externa utilizando reservas del Banco Central. Rifaron el principal resguardo que tiene la economía, para exhibir al gobierno como "pagador serial", a la espera de una respuesta amigable del mercado. Supusieron que los banqueros reingresarían las divisas que les entregaban los funcionarios y se abonó puntualmente una deuda pública resultante de infinitos canjes, sin investigar su origen y legitimidad.

Esta sucesión de fracasos ha sido coronada en el 2014 con el giro hacia la recreación del endeudamiento externo. Con ese objetivo se pagan las sentencias que emitió el tribunal del Banco Mundial (CIADI), a favor de cinco empresas afectadas por la pesificación que sucedió a la convertibilidad. También se reabrió por tercera vez el canje de títulos externos en litigio, para ofrecer un nuevo acuerdo a los fondos buitres. Estos financistas adquirieron por moneditas las 
acreencias argentinas desvalorizadas y ahora aguardan su pago integro en los tribunales de Nueva York. ${ }^{10}$

Por el simple arreglo de los litigios pendientes, la deuda externa volverá a crecer en forma muy significativa. La relación con el FMI es cada vez más cordial, desde que el gobierno aceptó la supervisión del organismo en la elaboración un nuevo índice de precios. Con el Club de Paris se llegó a un acuerdo de pago de las deudas contraídas durante la dictadura, se incrementaron sustancialmente los montos a cancelar y se reconocieron inadmisibles comisiones y punitorios.

El gobierno busca créditos externos luego de varios años de desembolsos que afectaron seriamente a las reservas. Presentó como un acto de "soberanía financiera" ese gran traspaso de fondos a los acreedores. Ahora intenta reiniciar un nuevo ciclo de endeudamiento de los entes estatales y provinciales. No sería la primera vez que con el lema de "financiar obras de infraestructura" se utilizan esos capitales para solventar los gastos corrientes.

Con el mismo objetivo de retomar el endeudamiento externo se ha indemnizado a Repsol, desconociendo la promesa de auditar el saqueo que consumó esa compañía. Algunos economistas describen esa capitulación como un logro, argumentando que el país necesita inversiones para recuperar el faltante energético. Pero olvidan que hasta hace pocos años Argentina exportaba combustible, mientras las reservas de petróleo y gas se desplomaban, generando el actual bache de importaciones. Este déficit no obedece al crecimiento de la economía. Simplemente hubo permisividad oficial frente a todos los incumplimientos de las compañías petroleras.

\section{Las fallas estructurales}

En las áreas más estratégicas hubo muchos discursos a favor de la industrialización, pero el modelo mantuvo intacto la creciente gravitación del extractivismo

10. Nuestra visión en: Katz, Claudio. ¿Cuántos buitres acosan a la Argentina? Argenpress, 01 jul. 2014. Disponible en: <http://www.argenpress.info/2014/07/cuantos-buitres-acosan-la-argentina.html>. 
minero-petrolero. Se impulsó especialmente un tipo de minería a cielo abierto que genera efectos devastadores sobre la Cordillera. Las empresas dinamitan montañas disolviendo rocas con materiales químicos contaminantes. Esta actividad destruye el medio ambiente sin crear empleo, ni generar desarrollo. Engrosa las ganancias de corporaciones internacionales que tributan bajos gravámenes.

Los defensores del modelo que reconocen estos problemas, pero argumentan que la reindustrialización ha sido el dato descollante. Remarcan no sólo esta recuperación frente a la liberalización financiera de los 90, sino también ante el resto de la región. ${ }^{11}$

Pero esta caracterización se basa en una repetida comparación con la depresión del 2001. Como pocas economías padecieron un colapso tan agudo, resulta muy sencillo demostrar la inédita envergadura de la recomposición fabril que tuvo Argentina. Se olvida que una vez repuestos los niveles tradicionales de producción y empleo, quedó reinstalada la misma estructura industrial dependiente y vulnerable del pasado. Por eso reapareció la elevada importación de insumos y la escasez de divisas para solventarlos. El déficit comercial del sector se expandió, al compás de crecientes compras externas de bienes y equipos.

La recuperación cíclica de la última década reforzó, además, la concentración y extranjerización de la industria. Como se mantuvo una ley de inversiones extranjeras que otorga total libertad para remitir utilidades, el grueso de las ganancias fueron giradas a las casas matrices.

Las empresas trasnacionales controlan la mayor parte de la actividad industrial y no realizan transferencias de tecnologías. Como el mercado argentino es marginal a sus estrategias globales, el nivel de reinversión local es muy bajo. El gobierno no sólo convalidó este escenario, sino que promovió un innecesario boom automotriz. El contraste entre esa expansión y el desplome del sistema ferroviario retrata hasta qué punto estuvieron invertidas las prioridades del desarrollo.

La reindustrialización quedó adicionalmente bloqueada por la consolidación de un sistema financiero pro-consumo y anti-inversión. Las pocas regu-

11. Kestelboim, Mariano. Reindustrialización. Página12, suplementos Cash, 28 abr. 2013. Disponible en: <http://www.pagina12.com.ar/diario/suplementos/cash/17-6771-2013-04-28.html>. 
laciones heterodoxas que se introdujeron para ordenar el mercado de capitales o actualizar la Carta Orgánica del BCRA, no alteraron la carencia de préstamos de largo plazo. Sólo multiplicaron la liquidez que manejan los bancos para motorizar la demanda.

El ocaso del ensayo neodesarrollista está reavivando en Argentina las convocatorias neoliberales a imitar las políticas de apertura y privatización de los gobiernos conservadores. Como ya se les pasó la euforia con España o Irlanda, ahora elogian a Perú y Colombia, exhibiendo sesgados indicadores de crecimiento o inversión. Nunca hablan de la vulnerabilidad financiera, que afrontan todos los modelos abiertos al ingreso y salida de capitales especulativos. Tampoco mencionan las dramáticas consecuencias del extractivismo que sufren las economías minero-exportadoras.

Los neoliberales auguran una lluvia de dólares cuando se "recupere la confianza en un buen gobierno", sin aclarar quién lucrará con esas divisas y cuánto costará su repago. También proponen extirpar el "populismo económico" y erradicar la perversa "intervención del estado". ${ }^{12}$

Pero suelen desconocer el intenso estatismo que caracterizó a todos los gobiernos pro-mercado. El gasto público nunca se redujo significativamente bajo esas administraciones. También ellos utilizaron los recursos del estado para subsidiar a los empresarios afines.

Al cabo de una década el neodesarrollismo tambalea. El modelo se distanció inicialmente del neoliberalismo, pero sin incluir las medidas requeridas para llevar a cabo la redistribución real del ingreso y el cambio de la matriz productiva. No modificó los pilares de una economía dependiente con gran desigualdad social.

\section{Tres interpretaciones en Brasil}

En Brasil existe un intenso debate sobre el neodesarrollismo y su grado de aplicabilidad al gobierno del PT (Partido de los Trabajadores). Esta controver-

12. Cortés Conde, Roberto. Acumular desequilibrios, la causa de las crisis recurrentes del país. La Nación, Economía, 15 sept. 2013. Disponible en: <http://www.lanacion.com.ar/1619871-acumular-desequilibrios-la-gran-causa-de-las-crisis-recurrentes-en-el-pais>. 
sia ilustra cuán discutible es la presencia de un modelo de ese tipo en la principal economía sudamericana.

Estas reservas provienen de la evidente continuidad que mantuvo el primer mandato de Lula con la política económica precedente. Allí estuvo totalmente ausente la ruptura que introdujo en Argentina el derrumbe de la convertibilidad.

La gestión inicial del sucesor de Fernando Henrique Cardoso sorprendió por la sintonía que mantuvo con su antecesor. La nueva gravitación social alcanzada por los trabajadores, no se plasmó en un proyecto diferenciado de las tradiciones dominantes. El PT llegó al gobierno con la explícita aprobación de los grandes grupos capitalistas. No irrumpió en forma imprevista como Kirchner y adoptó desde el inicio una postura extremadamente conformista. ${ }^{13}$

Por esta razón muchos autores utilizaron denominaciones complementarias del neoliberalismo (social-liberalismo, neoliberalismo atenuado) para caracterizar el primer período de Lula. En ese debut no se avizoraron elementos de giro neodesarrollista. Pero en el mandato posterior y en la administración de Dilma aparecieron ingredientes de un viraje que han suscitado tres caracterizaciones distintas.

Un primer enfoque considera que en estos períodos se consumó el pasaje hacia el neodesarrollismo. Estima que el recetario ortodoxo fue desechado y que Lula debió otorgar concesiones al gran capital (altas tasas de interés, sistema impositivo regresivo, preeminencia del agronegocio), para reintroducir la política industrial. Este curso es visto como una variante conservadora, que igualmente alentó la inversión pública y estimuló el consumo, mediante aumentos de la ayuda social y del salario mínimo. ${ }^{14}$

La segunda caracterización remarca el continuismo y la ausencia de rupturas con el neoliberalismo. Estima que el PT se amoldó al "Consenso Pos-Washington" con políticas económicas que estabilizaron el mismo curso de las últimas décadas. Sólo se introdujeron ciertas regulaciones en las priva-

13. Arcary, Valerio. Brasil dez anos de governos de coalizão dirigidos pelo PT, uma análise em perspectiva histórica. Adital, 27 mar. 2013. Disponible en: <http://site.adital.com.br/site/noticia. php?lang=PT\& cod $=74381>$.

14. Pomar, Valter. Notas sobre a politica internacional do PT. São Paulo: Secretaria de Relações Internacionais do PT, 2013. p. 23, 60-62, 79-92. (Textos para debate, v. 7.) 
tizaciones, algún control en la liberalización financiera y acotados límites a la apertura comercial.

Esta visión rechaza cualquier identificación del modelo de Lula con el neodesarrollismo, señalando que esta última tradición implica liderazgo de la burguesía industrial, sustitución de importaciones y posturas nacionalistas. Estima que ese legado contrasta con la primacía asignada a la exportación y a la liberalización comercial, en un marco de apertura al capital extranjero, desnacionalización y dependencia tecnológica. ${ }^{15}$. Otras variantes de este enfoque resaltan la continuada vulnerabilidad de la economía y de políticas ortodoxas encubiertas. ${ }^{16}$

Finalmente existe un tercer planteo intermedio. Señala que la experiencia gubernamental ha desmentido tanto a los aprobadores, como a los opositores del rumbo imperante. Estima que las corrientes neodesarrollistas al interior del gobierno fueron ganando posiciones frente a las vertientes monetaristas, hasta imponer correctivos a la etapa inicial. Estos cambios se plasmaron en nuevas políticas fiscales de estímulo productivo, inversión pública y expansión del Programa "Bolsa Familia".

Este giro se conceptualiza como una política híbrida, que permitió cierto crecimiento sin generar un programa coherente. La estrategia macroeconómica neoliberal del comienzo quedó entrelazada con iniciativas posteriores de cuño neodesarrollista. ${ }^{17}$

Esta caracterización destaca que en el segundo mandato Lula modificó la primacía inicial de los bancos a favor de la industria. Estima que consumó un viraje de altas tasas de interés y políticas de libre ingreso de capitales, a orientaciones que privilegian la actividad fabril, con subsidios financiados por la previsión social. Considera que el Lulismo tomó partido por las fracciones de

15. Gonçalves, Reinaldo. Novo desenvolvimentismo e liberalismo enraizado. Serviço Social \& Sociedade, São Paulo. n. 112, out.-dez. 2012.

16. Sampaio, Plínio de Arruda. Brasil. Hechos y mitos de los gobiernos. Diario Vive, 30 oct. 2012. Disponible en: $<\mathrm{http} / / / \mathrm{www}$.dariovive.org/?p=4439>.

17. Saad Filho, Alfredo; Morais, Lecio. Da economia política à política econômica: o novo desenvolvimentismo e o governo Lula. Revista de Economia Política, v. 31, n. 4, out.-dez. 2011. 
la burguesía que disputan con el capital financiero, resisten la desnacionalización y propician la protección del estado frente a sus rivales extranjeros. ${ }^{18}$

\section{Comparación entre dos países}

Las tres posturas en el debate brasileño divergen sobre el grado de incorporación de elementos neodesarrollistas al modelo económico del PT. Pero todas las posturas reconocen la gran distancia existente con la experiencia argentina. ${ }^{19}$

En ningún momento se insinuaron en Brasil medidas comparables a la nacionalización de los fondos de pensión o conflictos equivalentes al choque que opuso al gobierno argentino con el agronegocio. En los dos países hubo impulso al consumo, asistencialismo, políticas contracíclicas y fomento parcial a la reindustrialización. Pero el lulismo nunca introdujo las iniciativas neodesarrollistas que caracterizaron al kirchnersimo.

Esta diferencia obedece a la disparidad de escenarios político-sociales que han imperado en ambas naciones. El lulismo y el kirchnerismo constituyen dos variantes de las mismas administraciones de centro-izquierda. Pero se han desenvuelto en contextos muy distintos.

Mientras que el gobierno de Brasil acentuó durante su gestión la desmovilización social, el legado de la rebelión del 2001 obligó a sus pares del Cono Sur a gobernar con un ojo puesto en la reacción de los oprimidos. Recompusieron en Argentina el poder de los privilegiados, otorgando importantes concesiones democráticas y sociales al grueso de la población.

Lula no estuvo sometido a las presiones desde abajo que forzaron a los Kirchner a actuar en un tembladeral. El matrimonio K reconstruyó un estado colapsado por el desmoronamiento de la convertibilidad, frente a un PT que mantuvo casi intacta la estructura transferida por Cardoso.

18. Boito Jr., Armando. A economia capitalista está em crise e as contradições tendem a se aguçar. Brasil de Fato, São Paulo, n. 475, p. 5, 7 abr. 2012.

19. Una comparación en: Crespo, Eduardo (2013). "Es un mito...". Página12, suplementos Cash, 20 ene. 2013. Disponible en: <http://www.pagina12.com.ar/diario/suplementos/cash/17-6552-2013-01-20.html>. 
Esta diferencia explica la divergente incidencia del neodesarrollismo. En Argentina se ensayó un esquema con creciente regulación estatal, para recomponer un mercado interno devastado. En Brasil la continuidad socio-liberal inicial fue pausadamente sustituida por medidas de intervención, para contrarrestar la erosión generada por la ortodoxia monetarista. Condiciones políticas disímiles determinaron orientaciones económicas distintas.

Tal como ocurrió en Argentina desde el 2003, los indicadores económicos de Brasil comenzaron a mejorar a partir del 2006, provocando cierto desconcierto entre quiénes auguraban un rápido eclipse. El crecimiento de las reservas internacionales, la mejora de la posición externa de Brasil, la reducción de la pobreza absoluta y el aumento del crédito de consumo sorprendieron a muchos analistas.

Al igual que en Argentina este resultado obedeció a una combinación de condiciones externas favorables (bajas tasas de interés, afluencia de capital, mejora de los términos de intercambio) y políticas internas de apuntalamiento de la demanda. La escala de la recuperación económica fue inferior en Brasil, porque ese país no atravesó un desplome comparable al padecido por Argentina, ni contó con el rebote que generan esos colapsos.

Pero una vez concluido el ciclo ascendente, en ambos países afloran las mismas contradicciones de modelos que impulsan la demanda, sin remover las obstrucciones estructurales al desarrollo.

En el caso brasileño la tasa de crecimiento 2006-2013 ha sido muy baja en comparación a períodos precedentes y estuvo sostenida en esquemas de endeudamiento para expandir el consumo. La tasa de inversión (17-20\% del PBI) fue inferior a la media histórica y el pago de intereses de la deuda (40-45\% de la recaudación fiscal) continúa agobiando a la economía. ${ }^{20}$

El ascenso geopolítico que registra Brasil no se traduce en una expansión económica equivalente. Encabeza el bloque sudamericano, auspiciando políticas autónomas de regionalismo capitalista y se ha consolidado como subpotencia

20. Lucena, Eleonora de. Dilma precisa de coragem para colocar em prática o que fala, diz Carlos Lessa. Folha de S.Paulo, caderno Mercado, 14 jan. 2013. Disponible en: <http://www1.folha.uol.com. $\mathrm{br} /$ mercado/2013/01/1213859-dilma-precisa-de-coragem-para-colocar-em-pratica-o-que-fala-diz-carloslessa.shtml>. 
hemisférica. Pero su influencia es reducida en comparación a otras economías intermedias de Asia o Europa, que ganan espacio en el escenario global.

Un proyecto neodesarrollista industrializador choca en Brasil con la prioridad asignada a la agroexportación, en desmedro del desenvolvimiento manufacturero. El país depende cada vez más del agronegocio y esta limitación es incluso reconocida por las visiones más afines al modelo actual. ${ }^{21}$

El freno al desenvolvimiento industrial se verifica en la pérdida de competitividad y en la fuerte gravitación del denominado "costo Brasil". Esa obstrucción se corrobora, además, en el estancamiento tecnológico y en la obsolescencia de la infraestructura. Si en la segunda etapa del PT ganó espacio el lobby industrial, esa incidencia no ha generado una recuperación fabril significativa. Una gran distancia separa los esbozos actuales de neodesarrollismo de los viejos modelos centrados en la prioridad industrial. ${ }^{22}$

\section{¿Se masifica la clase media?}

Algunos pensadores estiman que los efectos benéficos del neodesarrollismo no se verifican en la estructura económica de Brasil, pero ya se corroboran en la expansión de la clase media. Destacan la consolidación de un nuevo segmento intermedio que reconfigura la fisonomía social del país. ${ }^{23}$

Pero esta caracterización sobredimensiona el ascenso del nuevo sector utilizando los mismos criterios que difunde el Banco Mundial. Este organismo postula que "la extensión de la clase media transforma a Latinoamérica", a partir de un inédito aumento de ese sector (30\%) entre el 2003 y el 2009.

21. Serrano, Franklin. Brasil debe ser la locomotora. Página12, El País, entrevista de Franklin Serrano a Javier Lewkowicz, 16 abr. 2013. Disponible en: $<$ http://www.pagina12.com.ar/diario/elpais/1-218827-201304-26.html>.

22. Carneiro, Ricardo de Medeiros. Velhos e novos desenvolvimentismos. Economia e Sociedade, Campinas, v. 21, dez. Disponible en: $<$ http://www.scielo.br/scielo.php?script=sci_arttext\&pid=S0104$06182012000400003>$.

23. García, Marco Aurelio. El nuevo desarrollismo. Revista Socialista, 31 oct. 2010. Disponible en: $<$ http://www.revistasocialista.com.ar/taxonomy/term/26>. 
Estos cálculos se basan en estimaciones inconsistentes que ubican en la clase media a cualquier trabajador que gane 10 dólares por día, más allá de las desigualdades imperantes en la sociedad. La pertenencia a una clase no se define en comparación a otros grupos, sino en función de la simple tenencia de cierto ingreso. Quiénes alcanzan ese piso quedan automáticamente ubicados fuera del universo de los humildes.

Con ese enfoque supone que la clase media se expande junto al aumento de la polarización social. La ampliación de ese segmento ya no atempera las brechas entre ricos y pobres, pero es igualmente retratada como un colchón intermedio. $^{24}$

El discurso de crecimiento de la clase media se generalizó en Brasil a partir de las mejoras registradas en el salario mínimo. Se incluyó dentro del nuevo estrato a todos los trabajadores que obtienen un ingreso per cápita entre 141 y 500 dólares mensuales. Con ese cálculo se afirma que el $54 \%$ de la población pertenece a la clase media. Pero esta conclusión es poco realista en un país que ocupa la posición 84 en el índice mundial de desarrollo humano. ${ }^{25}$

Ciertamente hubo mejoras sociales reales en la última década. La recuperación de los salarios más postergados, los incrementos obtenidos en las negociaciones de las convenciones colectivas y el mayor financiamiento educativo retratan esos desahogos. Los beneficiarios del Programa Bolsa Familia obtuvieron una importante tajada de estos avances.

Pero el grueso de los campesinos quedó afectado por la concentración de la tierra y la disminución de la desigualdad fue muy limitada, en un país donde el $10 \%$ de la población posee el $75 \%$ de la riqueza del país. Además, la tasa de explotación se mantuvo invariable y se profundizó la precarización mediante

24. Adamovsky, Ezequiel. El mito del aumento de la clase media. Clarín, Opinión, 26 dic. 2012. Disponible en: <http://www.clarin.com/opinion/mito-aumento-clase-media-global_0_835716476.html>. Gandásegui, Marco A. La clase media del Banco Mundial. Adital, Opinião, 13 dez. 2012. Disponible en: <http:// site.adital.com.br/site/noticia.php?lang $=\mathrm{PT} \& \operatorname{cod}=72805>$.

25. Berterretche, Luis. Los tramposos delirios de los tecnócratas del Banco Mundial. Argenpress, 10 abr. 2013. Disponible en: <http://www.argenpress.info/2013/04/los-tramposos-delirios-de-los.html>. Pasarinho, Paulo (2012). "El milagro propagandístico de la explosión de la clase media", 06 ago. 2012. Disponible en: $<$ http://www.vientosur.info/spip.php?article7023>. 
distintas formas de subcontratación. Un tercio de los nuevos empleos del período fueron absorbidos por los trabajadores terciarizados. ${ }^{26}$

La expansión de la clase media es frecuentemente identificada con la simple modernización del consumo. No se toma en cuenta que ese incremento de los volúmenes de compra se concretó con formas de crédito y tasas de interés poco sustentables. La persistencia de 30 millones de pobres cuestiona seriamente la presentación de Brasil como un país de segmentos medios. Se ha creado un nuevo círculo de ese sector, pero en un escenario de continuada segmentación social y convalidación del asistencialismo.

\section{Denominaciones y proyectos}

La caracterización del neodesarrollismo como un proyecto económico diferenciado del desarrollismo clásico y del neoliberalismo suscita fuertes controversias. Algunos autores cuestionan la especificidad de esta corriente, estimando que su nombre oculta meras intenciones y proyectos no realizados. Consideran que no existen logros acordes a los objetivos enunciados en el terreno de industrialización o el desenvolvimiento. ${ }^{27}$

Pero es muy frecuente la aparición de términos que aluden a ciertas metas sin guardar sintonía con su concreción. Como esta situación se verifica actualmente con el neodesarrollismo, conviene discutir el contenido del proyecto, evitando discusiones sobre la legitimidad de su nombre.

Si la validez del término asumido por cada enfoque estuviera determinada por el grado de cumplimiento del programa invocado, resultaría imposible cualquier clasificación. Nadie podría referenciarse en el socialismo (puesto que no existen sociedades igualitarias) o en el liberalismo (ante la ausencia de economías gobernadas por la pureza del mercado).

26. Sampaio, Plínio de Arruda (2012). Brasil. Hechos y mitos de los gobiernos. Diario Vive, 30 oct. 2012. Disponible en: $<$ http://www.dariovive.org/?p=4439>.

27. Cantamutto, Francisco J.; Costantino, Agostina (2013) Neodesarrollismo: ¿cuánto hay de nuevo? Revista Herramienta web 14, oct. 2013. Disponible en: <http://www.herramienta.com.ar/herramienta-web-14/ neodesarrollismo-cuanto-hay-de-nuevo>. 
Al igual que cualquier otro concepto político o económico, el neodesarrollismo pretende singularizar un proyecto representativo de ciertos sectores sociales. Es un error ignorarlo o descalificarlo por su distancia con el desarrollismo clásico. Sus propios promotores asumen esas diferencias, cuando utilizan el prefijo "neo" o el complemento "nuevo".

La crítica a esta corriente no debe recaer en la veneración del viejo desarrollismo, olvidando que tampoco ese antecesor cumplió con sus metas. El frustrado proceso de reindustrialización actual prolonga las dificultades que enfrentó la versión fallida de los años 1950-1960. Las contradicciones con la primera experiencia anticiparon los problemas que vuelven a emerger en la actualidad.

El principal debate entre los intérpretes del neodesarrollismo opone a quienes elogian y critican los propósitos (o resultados) de esa experiencia. En el caso de Argentina la postura favorable que asumen ciertos pensadores (Basualdo, Rinesi) contrasta con la mirada polémica que adoptan otros (Féliz). Nuestro enfoque se ubica en este segundo campo. ${ }^{28}$

Esta última visión busca comprender y cuestionar los cambios de modelos y políticas económicas, que se han registrado en América Latina en los últimos años. Estas modificaciones se procesan al interior de un mismo patrón de reproducción de exportaciones básicas. La complejidad del fenómeno justamente radica en la multiplicidad de vertientes que actúan dentro de la misma etapa del capitalismo.

\section{Maldiciones y repeticiones}

Es importante distinguir al neodesarrollismo del neoliberalismo, para notar cómo las diferencias en el plano económico se proyectan a la esfera

28. Basualdo, Eduardo (2011) Sistema político y modelo de acumulación: tres ensayos sobre la Argentina actual. Buenos Aires: Atuel. Rinesi, Eduardo (2011). Notas para una caracterización del kirchnerismo. Debates y Combates. Disponible en: <http://pt.calameo.com/read/00097706107c83b4bbc4c >. Féliz, Mariano (2013) "El neo-desarrollismo y la trampa de la renta extraordinaria. El caso de Argentina 2002-2012", Contrapunto, n. 2, jun., Montevideo. Katz, Claudio (2010) "Los nuevos desequilibrios de la economía argentina”, Batalla de Ideas, n. 1, año 1, sept., Buenos Aires. Disponible en: <http://www.argenpress.info/2014_07_18_archive.html>. 
política, en afinidades hacia gobiernos de centroizquierda o administraciones derechistas.

El neodesarrollismo no es una simple bandera demagógica de presidentes con discursos progresistas. Constituye la modalidad actual de los proyectos que periódicamente adoptan las elites, las altas burocracias o los grupos capitalistas de los países semiperiféricos. No es un programa en debate dentro Estados Unidos u Honduras. Irrumpe cíclicamente en el escenario político de Brasil, México o Argentina.

Este tipo de economías medianas necesitan retomar la industrialización. Cuentan con importantes mercados internos y masas de asalariados, pero sin el pilar que sostiene a esas estructuras en las potencias centrales. Han concluido hace mucho tiempo sus procesos de acumulación primitiva, pero enfrentan severas trabas periódicas para la acumulación de capital.

La consolidación internacional de una nueva gama de economías intermedias acentúa esta necesidad de recuperar el peso fabril. Pero este mismo escenario afecta las posibilidades de concreción de esa meta. Los países latinoamericanos que desenvolvieron su industrialización con cierto nivel de salarios, no pueden emular a los modelos asiáticos que expandieron la exportación manufacturera, a partir de mercados internos estrechos y carencias de recursos naturales. Las economías de la región necesitan expandirse aceleradamente, pero enfrentan espacios internacionales reducidos para materializar ese crecimiento.

Esta contradicción es muy severa para las naciones sudamericanas más afectadas que beneficiadas por la abundancia de recursos naturales. Ese excedente genera una altísima renta para bienes producidos a un costo inferior al promedio internacional. Este lucro se acrecienta cuando repunta el precio mundial de las materias primas, incentivando un rendimiento superior a la ganancia industrial.

Todos los programas desarrollistas han debido lidiar con esta contradicción, que induce a los capitalistas a evitar una actividad fabril de mayor riesgo y menor retorno que el negocio primarizado. Intentan revertir esta tendencia, canalizando porciones significativas de la renta hacia los emprendimientos industriales rehuidos por las clases dominantes. Implementan esta política mediante impuestos a las agroexportaciones y subsidios a los industriales. 
Las iniciativas neodesarrollistas resurgen periódicamente frente a las consecuencias de la perpetuación rentista. Si los grupos dominantes se resignan al status tradicional de sus países como exportadores de materias primas, la economía queda sujeta al vaivén internacional de los precios de esos productos, no genera empleo y sufre el ensanchamiento de las fracturas sociales. Es lo que ocurrió durante el neoliberalismo extremo de los años 1990.

Pero cuando los propios sectores dirigentes reaccionan con intervenciones estatales para utilizar la renta en procesos de industrialización, deben afrontar serios conflictos con los propietarios de ese excedente. Si pierden esa disputa se generan grandes crisis, que inducen al establishment a exigir un retorno a la situación precedente. Es lo que sucedió en Argentina en última década.

Esta oscilación histórica se ha repetido en numerosas oportunidades y por esta razón el neodesarrollismo actual reitera frustraciones ya conocidas. Pero como persiste el desequilibrio estructural que empuja a retomar el intento, ninguna decepción elimina la tendencia a volver una y otra vez sobre los mismos pasos.

La definición del desarrollismo como una "religión de la periferia capitalista" ilustra esta peculiar tendencia a la reiteración. Al concluir una experiencia fallida emerge la amnesia social que hace olvidar ese fracaso, pero al mismo tiempo se preparan las condiciones para repetir el experimento. ${ }^{29}$

Sólo otro proyecto con metas igualitarias, liderado por clases populares, y encarado con dinámicas de lucha consecuente podría ofrecer una salida a esa encerrona.

04 de julio de 2014.

Recebido em: 25/11/2014 - Aprovado em: 10/3/2015

29. Ouriques, Nildo (2012). Desarrollismo y dependencia en Brasil. Revista Pueblos, n. 51, 3 jun. 2012. Disponible en: $<$ http://www.revistapueblos.org/?p=2443>. 


\section{Referéncias bibliográficas}

AZPIAZU, Daniel; SCHORR, Martín. Hecho en Argentina: industria y economía, 1976-2007. Buenos Aires: Siglo XXI, 2010.

CASTELO, Rodrigo. O novo desenvolvimentismo e a decadência ideológica do pensamento econômico brasileiro. Serviço Social \& Sociedade, São Paulo, n. 112, out.-dez. 2012.

DAMILL, Mario; FRENKEL, Roberto. Las politicas macroeconómicas en la evolución reciente de la economía argentina. Buenos Aires: Cedes, 2009.

DE LA BALZE, Felipe et al. Argentina y Brasil enfrentando el siglo XXI.

Argentina y Brasil: enfrentando el siglo XXI. Buenos Aires: Asociación de Bancos de la República Argentina, 1995.

FONTES, Virginia. Novas encruzilhadas e velhos fantasmas. Encruzilhadas da América Latina no século XXI. Rio de Janeiro: Pão e Rosas, 2010.

KATZ, Claudio. "Los nuevos desequilibrios de la economía argentina". Anuario EDI, Buenos Aires: Economistas de Izquierda, n. 5, sept. 2010.

LOZANO, Claudio; RAMERI, Ana; Raffo,Tomás. Las transformaciones en la cúpula empresarial durante la última década. Aportes: Análisis económico, mayo 2009. Disponible en: <www.archivo.cta.org.ar>.

NEFFA, Julio (Coord.). La economía argentina y su crisis (1976-2001). Buenos Aires: CEIL-PIETTE CONICET, 2004.

PORTA, Fernando; BUGNA FERNÁNDEZ, Cecilia. El crecimiento reciente de la industria argentina. Nuevo régimen sin cambio estructural. . Crisis, recuperación y nuevos dilemas: la economía argentina 2002-2007. Buenos Aires: CEPAL, 2009.

ALMEIDA, Lúcio Flávio Rodrigues de. Entre o nacional e o neonacional-desenvolvimentismo. Serviço Social \& Sociedade, São Paulo, n. 112, oct.-dic. 2012.

SCHVARZER, Jorge. La industria que supimos conseguir. Buenos Aires: Ediciones Cooperativas, 2000.

ZAIAT, Alfredo. Plan Fénix para América del Sur. Página12, Economía, 12 nov. 2011. Disponible en: <http://www.pagina12.com.ar/diario/economia/2-181093-2011-11-12. html>. 